\title{
INFLUÊNCIA DO MOMENTO DE COLETA SOBRE A VIABILIDADE DE GRÃO DE PÓLEN EM MARACUJÁ-DOCE (Passiflora alata Curtis) ${ }^{1}$
}

\author{
RAQUEL SILVA COSTA², FABÍOLA VITTI MÔRO, JOÃO CARLOS DE OLIVEIRA
}

RESUMO - O objetivo deste trabalho foi verificar o melhor momento para a coleta do grão de pólen de Passiflora alata, com relação à sua maior viabilidade. Foram coletados 35 botões florais, 7 de cada horário de coleta (8h 40, um dia antes da antese, 8h 40, 10h 45 e 16h, no dia da antese e 8h 40, um dia após a antese). Os testes foram feitos por coloração e germinação in vitro. Utilizou-se o delineamento inteiramente casualizado, com 5 tratamentos e 7 repetições, e as médias foram comparadas pelo teste de Tukey, a 5\% de probabilidade. O teste de viabilidade por coloração variou de 69,64 (no dia da antese, 16 horas) a 75,91\% (um dia antes da antese). A porcentagem de germinação variou de 49,18 (24 horas após a antese) a 62,65\% (no dia da antese, 10h 45). O melhor momento de coleta do pólen, com relação à melhor viabilidade e germinação, é $10 \mathrm{~h} 45$, no dia da antese.

Termos para indexação: germinação do tubo polínico, polinização, teste de Alexander.

\section{INFLUENCE OF THE MOMENT OF THE COLLECT ON THE VIABILITY OF THE POLLEN OF SWEET PASSION FRUIT (Passiflora alata Curtis)}

\begin{abstract}
The aim of this work was to verify the best period to collect the pollen of Passiflora alata, with respect to its greater viability. Were collected 35 flower buds, 7 from each horary of collect (8h40, one day before anthesis, 8h40, 10h45 and $16 \mathrm{~h} 00$, in the day of anthesis and 8h40, one day after anthesis). The tests were made by coloring and in vitro germination. It was used the completely randomized design with 5 treatments and 7 repetitions and the averages were compared by Tukey's test at $5 \%$ of probability. The test of viability by coloring ranged of 69,64 (in the day of the anthesis, $16 \mathrm{~h} 00$ ) to $75,91 \%$ (one day before anthesis, 8h40). The percentage of germination ranged from 49,18 (24 hours after anthesis) to 62,65 \% (in the day of antese, 10h45). The best moment of collecting the pollen, with respect to the best viability and germination, is $10 \mathrm{~h} 45$, in the day of anthesis.
\end{abstract}

Index terms: germination of the pollen tube, pollination, Alexander Test.

\section{INTRODUÇÃO}

Os maracujás pertencem à família Passifloraceae, da ordem Passiflorales, que compreendem 12 gêneros e mais ou menos 500 espécies, com distribuição, principalmente, nos trópicos, na América, Ásia e África. No Brasil, a família é representada por apenas dois gêneros: Dilkea e Passiflora. O gênero Passiflora compreende trepadeiras herbáceas ou lenhosas, podendo apresentar-se como ervas e arbustos de hastes cilíndricas ou quadrangulares, angulosas, suberificadas, glabras ou pilosas. Diferem dos outros gêneros pela presença de 5 estames, 5 pétalas, 5 sépalas e pelo androginóforo ereto formado por estames de extremidades livres e com três estigmas (Teixeira et al., 1994). Nesse gênero, podemos encontrar cerca de 400 espécies de maracujá, a maioria originária da região Neotropical (América), sendo cerca de 120 nativas do Brasil (Bernacci et al., 2003).

A espécie Passiflora alata Curtis é conhecida popularmente por maracujá-guaçu (Leitão Filho \& Aranha, 1974), maracujá-doce, maracujá de refres-

${ }^{1}$ (Trabalho 236-08). Recebido em: 17-09-2008. Aceito para publicação em: 25-04-2009.

${ }^{2}$ Bióloga, Profa. Dra. Substituta - UNESP/Campus Experimental de Registro. Rua Nelson Brihi Badur, 430, Registro-SP. Cep: 11900000.raqscosta@yahoo.com.br

${ }^{3}$ Enga. Agrônoma, Profa. Dra. - Depto. Biologia Aplicada à Agropecuária - UNESP/FCAV. Via de acesso Prof. Paulo Donato Castellane, s/n, Jaboticabal-SP. Cep: 14884-900. Bolsista CNPq. fabiola@fcav.unesp.br

${ }^{4}$ Engo. Agrônomo, Professor Dr. Titular - Depto. Produção Vegetal/Fitotecnia - UNESP/FCAV. jocaoliv@fcav.unesp.br 
co, maracujá de comer, e maracujá-alado (Medina, 1980). É considerada nativa do Brasil e caracteriza-se por apresentar frutos com elevado valor nutritivo, boas qualidades gustativas, tamanho e aparência externa de grande aceitação, mostrando ser uma opção apropriada para ocupar não somente o mercado interno, como também o mercado externo de frutos in natura (Vasconcellos, 1991).

O cultivo do maracujá intensificou-se no início da década de 70 , com $P$. edulis e, não na mesma escala comercial, é também difundido o $P$. alata (Ruggiero et al., 1980). Os frutos são comestíveis, de sabor adocicado, e as folhas são sedativas e hipnóticas, usadas no tratamento de excitações nervosas, histerismos, neurastenia e nas perturbações da menopausa. Contém passiflorina, sedativo natural cianídrico, encontrado nas folhas, na proporção de 0,048\% (Souza \& Meletti, 1997).

As plantas da família Passifloraceae são dependentes da polinização cruzada para a formação do fruto, pela morfologia floral e por possuir grãos de pólen pesados e pegajosos, dificultando a polinização anemófila (Akamine \& Girolami, 1957). A alogamia é reforçada pela autoincompatibilidade do tipo homomórfica e esporofítica (Bruckner et al. 1995). Apesar de possuir uma flor completa, em maracujazeiro-amarelo ocorre um complexo sistema de autoincompatibilidade (Suassuna et al., 2003). Em maracujazeiro-amarelo, foi observado que a polinização influencia na frutificação, pois a quantidade de sementes e o conteúdo de suco estão correlacionados ao número de grãos de pólen depositados sobre o estigma durante a polinização (Akamine \& Girolami, 1959). Além disso, as flores dessa família também apresentam outras características que propiciam a ocorrência de polinização cruzada. São grandes, muito atraentes e coloridas, exalam forte odor e possuem néctar em abundância, localizado na base da corona (Semir \& Brown, 1975).

Para assegurar o sucesso nas hibridações controladas, é importante que o pólen a ser utilizado tenha boa viabilidade. Em geral, o pólen colhido de flores em adequado estádio de desenvolvimento e corretamente preparado não necessita de testes de viabilidade. Entretanto, não são raras as situações em que o pólen a ser usado tenha sido colhido em outra região ou, mesmo, fornecido por meio de intercâmbio com outros países. Muitas vezes, é necessário armazenar o pólen colhido em um ano, para ser utilizado no ano seguinte. Neste caso, é recomendável testar a viabilidade do mesmo antes de sua utilização (Einhardt et al., 2006).

O pólen tem maior viabilidade em condições ambientais (temperatura ambiente); assim, se este for submetido a diferentes condições artificiais de armazenamento, como congelamento ou manutenção em estufas com temperaturas constantes, a porcentagem de grãos capazes de germinar reduz-se rapidamente com o tempo de armazenamento (Bruckner et al., 2000).

O conhecimento do período de antese floral de uma espécie é muito importante em estudos sobre o grão de pólen da mesma. Segundo Teixeira et al. (1994), diferentes espécies de maracujá apresentam períodos de abertura floral distintos, mas quase sempre curtos, dificilmente passando de oito horas, e as horas de abertura e de fechamento são adaptadas aos períodos de atividade de polinizadores, específicos em cada região. Em geral, são abelhas de grande porte. Camillo (2003) relata que os polinizadores mais eficientes em maracujá-amarelo são as conhecidas popularmente como mamangavas (Xylocopa spp.) que, além de grande porte, realizam forrageamento na flor. Em Jaboticabal - SP, Rossine (1977) encontrou 99\% das flores de maracujá-doce (P. alata) abertas a partir das 07-09 horas e fechadas entre 18-19 horas, as quais, segundo Ruggiero (1996), permanecem abertas por apenas um dia.

São importantes os trabalhos que indicam o melhor momento de coleta do pólen para a obtenção de maior porcentagem de viabilidade do grão de pólen em processos de hibridações artificiais. De acordo com Nascimento et al. (2003), conhecer a viabilidade do grão de pólen é fundamental na produção de sementes híbridas, particularmente em espécies onde há a possibilidade de hibridação artificial.

De acordo com Galetta (1983), os métodos para se testar a viabilidade do pólen são agrupados em quatro tipos: por meio de corantes, germinação in vitro , germinação in vivo e porcentagem de frutificação efetiva.

O presente trabalho teve como objetivo verificar o melhor momento de coleta de polens de Passiflora alata, em que ocorra uma maior porcentagem de viabilidade.

\section{MATERIAL E MÉTODOS}

O trabalho foi realizado na Faculdade de Ciências Agrárias e Veterinárias, Câmpus de Jaboticabal da Universidade Estadual Paulista (FCAV/ UNESP). O material utilizado foi obtido da coleção de maracujazeiros, pertencente ao Departamento de Produção Vegetal.

Realizaram-se dois testes de viabilidade: um pelo método de Alexander (1980) e outro pelo método de germinação in vitro (Cheng \& Freeling, 1976). 
Foram coletadas 35 flores, escolhidas aleatoriamente de várias plantas da coleção, sendo 7 flores em cada horário de coleta. Estas flores foram recobertas com sacos de papel, um dia antes de ocorrer a abertura floral (no estádio de botão floral), para impedir a perda e a mistura de pólen, caso fossem visitadas por insetos polinizadores.

A coleta do pólen foi realizada nos seguintes horários: um dia antes da antese de botões florais, (às 8h 40), no dia da antese (às 8h 40, às 10 h 45 e às 16 h) e um dia após a antese (às 8h 40). Em cada momento, foram coletadas 7 flores, e as anteras foram removidas com uma pinça de ponta fina.

Para a avaliação da viabilidade, pelo método de coloração de Alexander (1980), os grãos de pólen foram retirados com o auxílio de um pincel e colocados em lâminas histológicas contendo uma gota do corante.

As lâminas foram cobertas com lamínula e vedadas com esmalte incolor. Foram preparadas 4 lâminas por flor e, em cada lâmina, foram contados, em microscópio óptico, os grãos de pólen viáveis (coloração vermelha) e inviáveis (coloração verde), em 10 campos por lâmina.

Com relação à germinação in vitro, foram utilizadas duas placas de Petri por flor, contendo o meio de cultura descrito por Cheng \& Freeling (1976). O pólen foi distribuído sobre o meio de cultura, e as placas foram colocadas no escuro. Após 2 horas, aproximadamente, foi observado, em estereomicroscópio, o número de grãos de pólen germinados, em 10 campos por placa, num total de 20 campos. Foram considerados grãos de polens germinados os que apresentaram tubo polínico de comprimento maior ou igual ao diâmetro do grão de pólen.

Após a contagem, foram feitos cálculos para a obtenção da porcentagem de germinação e viabilidade em cada momento de coleta. A análise estatística dos dados foi feita pelo delineamento inteiramente casualizado (DIC), com cinco tratamentos e sete repetições, e as médias foram comparadas pelo teste de Tukey, a 5\% de probabilidade.

\section{RESULTADOS E DISCUSSÃO}

O conhecimento do estádio adequado de coleta do botão floral é essencial quando se quer obter polens maduros com o máximo de viabilidade, para armazenar e possibilitar cruzamentos específicos (Menck, 1990).

De acordo com os dados da análise estatística, apresentados na Tabela 1, observa-se que não houve diferença significativa entre os tratamentos para a viabilidade dos grãos de pólen de P. alata, pelo método de coloração. A média de viabilidade foi de 71,95\%, variando de 69,64 (no dia da antese, às 16 horas) a $75,91 \%$ (um dia antes da antese). A viabilidade reduziu-se ao longo da antese, com 69,91\% após 24 horas de abertura floral. Ruggiero et al. (1996) consideram que acima de $70 \%$ é ainda um alto percentual de viabilidade. Souza et al. (2002) observaram que os grãos de polen, em maracujazeiro-amarelo, apresentaram alto percentual médio de viabilidade polínica na antese $(93,7 \%)$, que permaneceu alto (acima de 75\%) por, pelo menos, 24 horas após a abertura da flor. Contudo, observaram que o momento de coleta dos polens, assim como no presente trabalho, também influenciou negativamente no percentual médio de viabilidade ao longo do período de coleta.

Para Báez et al. (2002), o corante carmim acético e a solução de Alexander, usados na indicação de viabilidade polínica, refletem somente a integridade de estruturas celulares, como núcleo e membrana plasmática. Alexander (1980) diz que, por meio da solução de Alexander, é possível diferenciar os grãos de pólen abortados dos não abortados, pois os últimos não possuem o núcleo, e apenas a celulose contida na parede apresentará coloração.

Um bom pólen deve apresentar 50 a $80 \%$ de germinação, com tubos bem desenvolvidos (Scorza \& Sherman, 1995). A porcentagem de germinação in vitro diferenciou-se entre os horários de coleta, onde foi significativamente menor para os grãos de pólen de flores fechadas, coletadas um dia antes de sua abertura (4,06\%), embora estivessem com alta taxa de viabilidade, pelo método de coloração. Os demais tratamentos não apresentaram diferenças estatisticamente significativas entre si, embora tenha sido notado que houve uma tendência de diminuição da porcentagem de germinação, na medida em que a coleta tenha sido efetuada num momento mais distante da antese, variando de 49,18 (24 horas após a antese) a 62,65\% (no dia da antese, às 10h 45).

O grão de pólen, na abertura da flor, necessita estar plenamente viável e, geralmente, à medida que o tempo avança, a viabilidade do grão de pólen vai diminuindo e reduzindo sua eficiência na fertilização (Souza et al., 2002). Á medida que o pólen envelhece, o comprimento do tubo polínico e a porcentagem de germinação decrescem (Scorza \& Sherman, 1995; Einhardt et al., 2006).

Resultados de pesquisa mostram que a porcentagem de germinação e a porcentagem de viabilidade do pólen estão em completa acordância (Bolate \& Pirlak, 1999). Há observações de que o método do corante superestima a porcentagem de germinação do pólen, enquanto o teste in vitro a subestima (Galetta, 1983). Einhardt (2006), após comparação 
de métodos para testar a viabilidade de pólen de pessegueiro, conclui que a utilização da germinação in vitro fornece resultados satisfatórios em relação à germinação in vivo, e a coloração por carmim propiônico superestima a porcentagem de polens viáveis. No presente estudo, foi observado que o momento de coleta de grãos de pólen às $10 \mathrm{~h} 45$, no dia da antese floral, além de apresentar alta viabilidade, pelo teste de Alexander, é o de maior porcentagem de germinação in vitro. Portanto, pode-se considerar o melhor momento de coleta. Segundo Franzon \&
Raseira (2006), o período ideal para a coleta de pólen de Eugenia involucrata, uma Myrtaceae, é logo após a antese. Como já dito, Rossine (1977) relata a abertura de flores do maracujazeiro-doce entre 07 e 09 horas, e o melhor momento encontrado no presente trabalho também é próximo da abertura floral.

A determinação do melhor momento de coleta do grão de pólen, com relação à viabilidade e germinação, pode ser utilizada em programas de melhoramento do maracujá-doce, fornecendo os melhores momentos para se realizarem hibridações manuais.

TABELA 1- Porcentagem de viabilidade de grãos de pólen em P. alata.

\begin{tabular}{ccc}
\hline Tratamento & Coloração & Germinação “in vitro” \\
\hline Dia anterior à antese & $75,91 \mathrm{a}$ & $4,06 \mathrm{~b}$ \\
No dia da antese (8h 40) & $70,08 \mathrm{a}$ & $61,94 \mathrm{a}$ \\
No dia da antese (10h 45) & $74,19 \mathrm{a}$ & $62,65 \mathrm{a}$ \\
No dia da antese (16 h) & $69,64 \mathrm{a}$ & $55,88 \mathrm{a}$ \\
Dia posterior à antese & $69,91 \mathrm{a}$ & $49,18 \mathrm{a}$ \\
\hline Média & 71,95 & 46,74 \\
\hline CV\% & 9,55 & 24,07
\end{tabular}

Médias seguidas de mesma letra na coluna não diferem entre si, pelo teste de Tukey, a 5\% de probabilidade.

\section{CONCLUSÕES}

1-A viabilidade do pólen de $P$. alata é relativamente constante durante todo o período da antese floral e até um dia após a mesma.

2-A porcentagem de germinação in vitro, do grão de pólen, é extremamente baixa no dia que precede a antese floral, mesmo que os grãos de pólen tenham alta taxa de viabilidade.

3-O melhor momento de coleta dos grãos de pólen, considerando-se a maior porcentagem de viabilidade pela coloração e pela germinação, é às 10h 45, no dia da antese.

\section{AGRADECIMENTOS}

À Roseli Conceição Silva, técnica do laboratório de Morfologia Vegetal, da Faculdade de Ciências Agrárias e Veterinárias de Jaboticabal - SP, pela colaboração na execução do presente.

\section{REFERENCIAS}

AKAMINE, E. K.; GIROLAMI, D. G. Pollination and fruit set in yellow passion fruit. Honolulu: Hawaii Agricultural Experiment Station, 1959. 44 p. (Technical Bulletin, 39).

AKAMINE, E. K.; GIROLAMI, D. G. Problems in fruit set in yellow passion fruit. Hawaii Farm Science, Honolulu, v. 5, n. 4, p. 3-5, 1957.

ALEXANDER, M.P. A versatile stain for pollen fungi, yeast and bacteria. Stain Technology, Baltimore, v. 55. n. 1, p. 13-18, 1980.

BAÉZ, P.; RIVEROS, M.; LEHNEBACH, C. Viability and longevity of pollen of Nothoagus species in south Chile. New Zealand Journal of Botany, Wellington, v. 40, p. 671-678, 2002.

BERNACCI, L. C.; VITTA, F.A.; BAKKER, Y. V. Passifloraceae. In: WANDERLEY, M.G.L.; SHEPPERD, G.J.; MELHEM, T.S.; GIULIETTI, A.M.; KIRIZAWA, M. (Eds.). Flora Fanerogâmica do Estado de São Paulo. São Paulo: RiMa/FAPESP, 2003. v. 3, p. 247-274. 
BOLAT, Y.; PIRLAK, L. Na investigation on pollen viability, germination and tube growth in some stone fruits. Turkish Journal of Agriculture Forestry, Ankara, v. 23, p. 383-388, 1999.

BRUCKNER, C. H.; CASALI, V. W. D.; MORAES, C. F.; REGAZZI, A. J.; SILVA, E. A. M. Selfincompatibility in passion fruit (Passiflora edulis Sims). Acta Horticulturae, Kecskemét, v. 370, p. 45-57, 1995.

BRUCKNER, C. H.; SILVA, M. M.; FALLEIRO, T. M.; ANDRADE, B. B; MOREIRA, A. E. Viabilidade do pólen de maracujazeiro sob diferentes condições de armazenamento. Revista Ceres, Viçosa, v. 47, n. 273, p.1-9, 2000.

CAMILLO, E. Polinização do maracujá. Ribeirão Preto: Holos Editora, 2003. 44 p.

CHENG, D. S. K.; FREELING, M. Methods of maize pollen germination in vitro, collection storage, and treatment with toxic chemicals: recovery of resistant mutants. Maize Genetics Cooperation Newsletter, Columbia, v. 50, p. 11-13, 1976.

EINHARDT, P. M.; CORREA, E. R.; RASEIRA, M. do C. B. Comparação entre métodos para testar a viabilidade de pólen de pessegueiro. Revista Brasileira de Fruticultura, Jaboticabal, v. 28, n. 1, p. 5-7, 2006.

FRANZON, R. C.; RASEIRA, M. C. B. Germinação in vitro e armazenamento do pólen de Eugenia involucrata DC (Myrtaceae). Revista Brasileira de Fruticultura, Jaboticabal, v. 28, n. 1, p. 18-20, 2006.

GALLETTA, G. J. Pollen and seed management. In: MOORE, J. N.; Janick, J. (Ed.). Methods in fruit breeding. West Lafayette: Purdue University Press, 1983. p. 23-47.

LEITÃO FILHO, H. F.; ARANHA, C. Botânica do maracujazeiro. In: SIMPÓSIO DA CULTURA DO MARACUJÁ, 1., 1971, Campinas. Anais... São Paulo: Sociedade Brasileira de Fruticultura, 1974. p. 13.
MEDINA, J. C. Cultura. In: GARCIA, J. L. M.; LARA, J.C.C.; TOCCHINI, R.P.; HASHIZUME, T.; MORETTI, V.A.; CANTO, W.L. Maracujá: da cultura ao processamento e comercialização. Campinas: ITAL, 1980. cap.1, p. 5-105. (Série Frutas Tropicais, 9).

MENCK, A. L. M.; ODA, S.; MARCHI, E. L.; KOVALSKI, M. E. Influência do sistema de coleta de botões florais na viabilidade de pólen de Eucalyptus spp. IPEF, Suzano, v. 44, n. 43, p. 20-23, 1990.

NASCIMENTO, W. M.; TORRES, A. C.; LIMA, L. B. Pollen viability in hybrid seed production off eggplant under tropical conditions. Acta Horticulturae, Bélgica, p. 37-39, 2003.

ROSSINI, A. de C. Características Botânicas e Agronômicas de Plantas de Passiflora alata Ait. (Maracujá-açu) cultivadas em Jaboticabal. 1977. 46 f. Monografia (Graduação em Agronomia) - Faculdade de Ciências Agrárias e Veterinárias, Universidade Estadual Paulista, Jaboticabal, 1977.

RUGGIERO, C. Cultura do maracujazeiro. Jaboticabal: FCAV-UNESP, 1980. 147 p.

RUGGIERO, C.; SÃO JOSÉ, A. R.; VOLPE, C. A.; OLIVEIRA, J. C. de; DURIGAN, J. F.; BAUMGARTNER, J. G.; SILVA, J. R. da; NAKAMURA, K.; FERREIRA, M. E.; KAVATI, R.; PEREIRA, V. P. Maracujá para exportação: aspectos técnicos da produção. Brasília: Embrapa, 1996. 64 p. (Série Publicações Técnicas Frupex, 19).

SCORZA, R.; SHERMAN, W. B. Peaches. In: JANIK, J.; MOORE, J. N. (Eds.). Fruit breeding. New York: John \& Sons, 1995. p. 325-440.

SEMIR, J.; BROWN, K. S. Jr. Maracujá: a flor da paixão. Revista Geográfica Universal. São Paulo, v. 5, n. 2, p. 40-47. 1975.

SOUZA, J. S. I.; MELETTI, L. M. M. Maracujá: espécies, variedades, cultivo. Piracicaba: FEALQ, 1997. 179 p. 
SOUZA, M. M. de; PEREIRA, T. N. S.; MARTINS, E. R. Microsporogênese e microgametogênese associadas ao tamanho do botão floral e da antera e viabilidade polínica em maracujazeiro-amarelo (Passiflora edulis Sims f. flavicarpa Degener). Ciência Agrotecnologia, Lavras, v. 26, n. 6, p. 1209-1217, 2002.

SUASSUNA, T. M. F.; BRUCKNER, C. H.; CARVALHO, C. R.; BOREM, A. Self-incompatibility in passionfruit: evidence of gametophytic-sporophytic control. Theoretical and Applied Genetics, Berlin, v. 106, n. 2, p. 298-302, 2003.
TEIXEIRA, C. G.; CASTRO, J. V.; TOCCHINI, R. P.; NISIDA, A. L. A. C.; HASHIZUME, T.; MEDINA, J. C.; TURATTI, J. M.; LEITE, R. S. da S. F.; BLISKA, F. M. de M.; GARCIA, E. B. Maracujá: cultura, matéria-prima, processamento e aspectos econômicos. 2. ed. Campinas: ITAL, 1994. 267 p. (Série Frutas Tropicais).

VASCONCELLOS, M. A. S. Biologia floral do maracujá-doce (Passiflora alata Dryand) nas condições de Botucatu-SP. 1991. 99 f. Dissertação (Mestrado em Agronomia) - Faculdade de Ciências Agronômicas, Universidade Estadual Paulista, Botucatu, 1991. 